\title{
Respiratory Effects of Lactic Acid Injected into the Jugular Vein of Newborn Rabbits
}

\author{
GENEVIEVE DUCROS AND TERESA TRIPPENBACH
}

Department of Physiology, McGill University, Montreal, Quebec, Canada H3G IY6

\begin{abstract}
To define respiratory effects of peripheral acidemia during early development, we injected lactic acid (LA) into the jugular vein of 32 1- to 7-d-old rabbit pups and four adult rabbits. The body weight of newborns varied between $67 \pm 17 \mathrm{~g}$ in 1-d-old and $119.8 \pm 33.7 \mathrm{~g}$ in $7-\mathrm{d}-$ old animals versus $4 \pm 0.1 \mathrm{~kg}$ in adults. Animals were anesthetized with ketamine $(30 \mathrm{mg} / \mathrm{kg})$ and urethane $(0.6-$ $1.2 \mathrm{~g} / \mathrm{kg}$ ), tracheotomized, and breathed spontaneously. Diaphragmatic electromyogram, tidal volume, esophageal pressure, and arterial pressure were recorded. In adult rabbits, a LA dose of $0.25 \mathrm{mM} / \mathrm{kg}$ elicited an increase in the rate of breathing with no change or a decrease in tidal volume (early response), followed by a deep and fast respiration (late response). The same LA dose had no effect or provoked only the late response in 1- and 2-d-old rabbits and led to the early and late responses in older newborns. The early response was abolished and the late response was diminished after vagotomy. Our results suggest that the early response is mediated by vagal afferents and the late response, although modified by vagal imput, is of an extravagal origin. It is suggested that acidemia may be involved in the transient tachypnea syndrome in newborn infants. Possible contribution of vagal nonmyelinated endings in triggering the early response to LA is discussed. (Pediatr Res 29: 548-552, 1991)
\end{abstract}

\section{Abbreviations}

LA, lactic acid

EMGdi, integrated activity of the diaphragm

VT, tidal volume

$\mathrm{VE}$, minute ventilation

VT/TI, mean inspiratory flow

TI, inspiratory time

TE, expiratory time

Pes, esophageal pressure

$\mathrm{Pa}$, mean arterial pressure

The first deep and slow breath taken at birth is followed by tachypnea lasting up to $90 \mathrm{~min}$ in infants delivered vaginally or by cesarean section. Already during the first day of life, respiration becomes deeper and slower (1). However, in some cases tachypnea may persist for up to $5 \mathrm{~d}$ of postnatal life. The latter instance has been described as the transient tachypnea syndrome attributed to a delay in absorption of fluid from the lungs in otherwise healthy newborns (2). In these infants, roentgenographic examination showed pulmonary edema, pulmonary vascular prominence, and local hyperinflation of the lung. Gradual

Received Junc 14, 1990; accepted January 29, 1991.

Correspondence: Dr. Teresa Trippenbach, Department of Physiology, McGill University, 3655 Drummond St., Montreal, Quebec, Canada H3G 1 Y6.

Supported by the Medical Research Council of Canada and the Hospital for Sick Children Foundation, Toronto, Canada. decrease in the breathing frequency to normal levels has a time course similar to that of clearing of the roentgenographic abnormalities (3).

In newborn lambs with radiologic evidence of lung fluid, moderate to severe hypoxemia and acidemia were found after the onset of breathing (4). Several authors reported that hypoxia of different origin is also associated with acidemia in newborn and adult animals. For example, in conscious newborn lambs, before oral breathing was initiated, nasal obstruction for no longer than $15 \mathrm{~min}$ resulted in asphyxia and reduction in arterial $\mathrm{pH}$ that was more pronounced the younger was the animal (5). Administration of hypoxic mixture was associated with elevated tissue levels of lactic acid (6) and brain acidosis in adult rats (7). In contrast, brain stem extracellular acidosis without reduction in plasma $\mathrm{pH}$ was recorded during hypoxia in anesthetized, paralyzed, and artificially ventilated piglets (8). However, anesthesia and mechanical ventilation could prevent the shift from aerobic to anaerobic metabolism that would occur in conscious and spontaneously breathing hypoxic animals.

Respiratory effects of LA in newborns are unknown. In adult animals, LA, when introduced to pulmonary circulation, evokes a rapid and shallow breathing pattern $(9,10)$. Thus, it is possible that acidemia may contribute to the development of tachypnea in awake or decerebrated hypoxic animais (11-13) and transient tachypnea syndrome in newborn infants (2). To test this hypothesis, we examined respiratory effects of LA injected into the jugular vein in spontaneously breathing newborn and adult rabbits.

\section{MATERIALS AND METHODS}

Experiments were conducted on 32 newborn ( 1 to $7 \mathrm{~d}$ old) and four adult rabbits. All rabbits were premedicated with intramuscular injection of ketamine $(30 \mathrm{mg} / \mathrm{kg}$, Ketaset; Rogar $/ \mathrm{STB}$ : Inc., Montreal, Quebec, Canada) and anesthetized with intraperitoneal injection of urethane. The dose of urethane necessary tc eliminate pain was estimated by the absence of "paw withdrawal" reaction and varied between animals from $600 \mathrm{mg} / \mathrm{kg}$ to $1.2 \mathrm{~g}$ / $\mathrm{kg}$.

In all rabbits, skin on the neck was cut on the midline and the trachea was cannulated. In newborns, a jugular vein and a carotic artery were catheterized. In the adults, catheters were insertec into a jugular vein and a femoral artery. Both vagi were separatec from the surrounding tissues and prepared for later sectioning A fine copper bipolar electrode was sewn into the diaphragn next to the sternum via an abdominal incision that was ther closed.

The signal from the diaphragmatic electrode was amplifier (Grass P511-H amplifier; Grass Instrument Co., Quincy, MA) rectified, and processed by a modified Paynter filter (13a) witl an averaging time of $100 \mathrm{~ms}$. The output from the filter is caller the integrated activity. VT was obtained by integration of th flow signal from the custom made pneumotachograph. Th arterial catheter was attached to a pressure transducer (mode no. 21080A; Hewlett-Packard Co., Palo Alto, CA) for arteric 
pressure measurements. Esophageal pressure was recorded by means of a water-filled catheter (time constant of $0.6 \mathrm{~s}$ ) placed in the lower third of the esophagus and connected to a differential pressure transducer (Hewlett-Packard model no. 270). Esophageal and blood pressure signals were fed into carrier amplifiers for signal conditioning. Skin temperature in newborns and rectal temperature in adults was measured with a thermoprobe and kept constant at $36 \pm 0.5$ and $37 \pm 1.0^{\circ} \mathrm{C}$, respectively.

LA was prepared from an $85 \%$ stock solution, so that $1 \mathrm{~mL}$ contained $1 \mathrm{mmol}$ of LA. Injections were made into the jugular vein catheter with a dead space of $0.05 \mathrm{~mL}$ and immediately flushed with $0.05 \mathrm{~mL}$ of warm saline. A dose of $0.25 \mathrm{mM} / \mathrm{kg}$ body weight was used in all animals. In the adults (body weight $4.0 \pm 0.1 \mathrm{~kg}$ ), it represented a bolus injection of $1 \mathrm{~mL}$. A similar dose was obtained by injecting $0.015 \mathrm{~mL}$ in the 1 - to 3 -d-old rabbits with body weights varying from $65 \pm 17$ to $74.3 \pm 14.3$ $\mathrm{g}$, and $0.025 \mathrm{~mL}$ in the 5 - to 7 -d-old rabbits with body weights varying from $104.4 \pm 26.6$ to $119.8 \pm 33.7 \mathrm{~g}$. Our preliminary observation showed that the LA dose of $0.8 \mathrm{mM} / \mathrm{kg}$ was the threshold dose for rabbits during their first day of life (14). Therefore, this dose was given to animals during the first $2 \mathrm{~d}$ of life. To evaluate the dose dependence of the response in six rabbits during their first $2 \mathrm{~d}$ of life, LA doses were increased to 1.2 and $1.5 \mathrm{mM} / \mathrm{kg}$. To evaluate the threshold dose and dose dependence of the response in older newborns, increasing LA doses from 0.05 to $1.0 \mathrm{mM} / \mathrm{kg}$ were given in six experiments on 3- to 7-d-old rabbits. The results showed that $0.5 \mathrm{mM} / \mathrm{kg}$ is the saturation dose. Therefore, this dose was repeated in all newborns between the 3rd and 7th day of age. We allowed 10 min between injections of different LA doses for the breathing pattern to return to normal. A bolus injection of $0.1 \mathrm{~mL}$ and $1 \mathrm{~mL}$ of saline was given through the jugular vein before LA injections in all newborn and adult animals, respectively. These volumes corresponded to the largest LA doses used in both populations.

Data analyses. EMGdi, VT, Pes, and Pa were recorded on a six-channel pen recorder (Brush 260; Gould, Inc., Cleveland, $\mathrm{OH})$ at a paper speed of $25 \mathrm{~mm} / \mathrm{s}$. Records of VT and EMGdi were digitized with graphic tablets (Hewlett-Packard model no. 911A) connected to a microcomputer (Hewlett-Packard model no. 85). Peak amplitude of Pes recorded during inspiration and $\mathrm{Pa}$ were measured manually. Both respiratory phases were measured from the records of EMGdi. TI was defined as the interval from the onset of EMGdi to its rapid decline. The latter was also taken as the onset of expiratory phase (TE). The following variables were considered in data analyses: VE, respiratory rate, VT, VT/TI, peak EMGdi, TI, and TE. Ten to 20 control breaths were measured before saline and before each LA injection. Before vagotomy, effects of LA were complex and often two types of effects were observed. The early response was recorded after a delay of less than $1 \mathrm{~s}$ and was characterized by rapid respiratory rate sometimes accompanied by a decrease in VT and an increase in end-expiratory volume. Duration of this response varied between 0.8 and $7 \mathrm{~s}$ (mean $3.87 \pm 2.40 \mathrm{~s}$ ) in different animals. Because of the delay and variability in duration of the early response, we analyzed all breaths recorded for $2 \mathrm{~s}$ after the first noticeable effect in all animals. The early response was always followed by a late response. The late response, lasting for 3 to 5 min, was characterized by a deep, fast, and regular pattern of breathing. To evaluate changes in the pattern of breathing during this response, 10 breaths were measured $10 \mathrm{~s}$ after the injections. The same was done after saline injection and after vagotomy. Finally, 10 breaths were measured at each minute of a 10 -min recovery period after $L A$ in both intact and vagotomized rabbits.

For each sample of data, the mean and SD of absolute values and values normalized to their controls were calculated in individual animals. Next, group mean values were calculated.

Two-way analysis of variance tests for repeated measures and the two-tailed $t$ test for two means were used where applicable to evaluate age-related differences, dose dependence, and significance of response within each age group. These analyses were based on absolute and normalized values expressed as a percentage of control before LA injection in individual rabbits. Values were considered to be significantly different if $p<0.05$.

\section{RESULTS}

Injection of saline into the jugular vein did not change the pattern of breathing in newborn and adult rabbits.

In the adult animals, LA in the dose of $0.25 \mathrm{mM} / \mathrm{kg}$ evoked a transient increase in end-expiratory volume (by $35.6 \pm 13.3 \%$ of control VT) and a decrease in Pes (by $0.82 \pm 0.25 \mathrm{~cm} \mathrm{H}_{2} \mathrm{O}$ ), with superimposed shallow and rapid breaths (early response) followed by the return to normal end-expiratory volume and a regular, deep, and fast breathing pattern (late response).

Early response. Preliminary analyses indicated significant differences in the response to LA in 1-to 2-d-old, 3-to 7-d-old, and adult rabbits. Therefore, the following data are presented in three groups: group 1, 1- and 2-d-old newborns ( $n=11)$; group 2, 3to 7-d-old rabbits $(n=21)$; and group 3, adult animals $(n=4)$. In Figure 1, we compared the carly response to LA in the dose of $0.25 \mathrm{mM} / \mathrm{kg}$ in these three groups of animals. In group 1 . changes in all ventilatory variables were not significant. In group 2 , VE increased by $149.3 \pm 126.3 \%$, VT/TI increased by $63.7 \pm$ $57.0 \%$, and TE decreased by $51.1 \pm 33.6 \%$. In group $3, \mathrm{VE}$ increased by $98.6 \pm 41.7 \%$, VT/TI increased by $57.2 \pm 14.4 \%$, EMGdi increased by $78.9 \pm 67.6 \%$, and TE decreased by $51.3 \pm$ $33.4 \%$. Despite a great variability, all of these changes were significant. Only the EMGdi response was significantly different between group 2 and group 3 .

The group mean VT/Pes ratio decreased by $19.4 \pm 8.3 \%(p<$ $0.05)$ in the adult rabbits. This ratic was unaffected in newborns, suggesting that the dynamic mechanical properties of the lungs were undisturbed after an LA dose of $0.25 \mathrm{mM} / \mathrm{kg}$ in rabbits during their first week of life.

In contrast to the adult rabbits, the early response evoked by $0.25 \mathrm{mM} / \mathrm{kg}$ was never accompanied by an increased end-expiratory level in newborns. The latter was observed in only six pups of different ages after LA doses raging between 0.50 and 1.2 $\mathrm{mM} / \mathrm{kg}$. Examples of this response recorded after a dose of 0.80 $\mathrm{mM} / \mathrm{kg}$ in 1- and 2-d-old rabbits are illustrated in Figure 2. After these large LA doses, the VT/Pes ratio slightly decreased, but the decrease was not significant in newborns. Similar to the 1-d-old rabbit of Figure 2, in other animals a decrease in Pa observed after LA was recorded several seconds after the injection, at which time the late response was already well established. Pa returned to normal within $1 \mathrm{~min}$, and increased VT, respiratory frequency, and EMGdi were recorded for another 3 to $5 \mathrm{~min}$. Bradycardia was never observed.

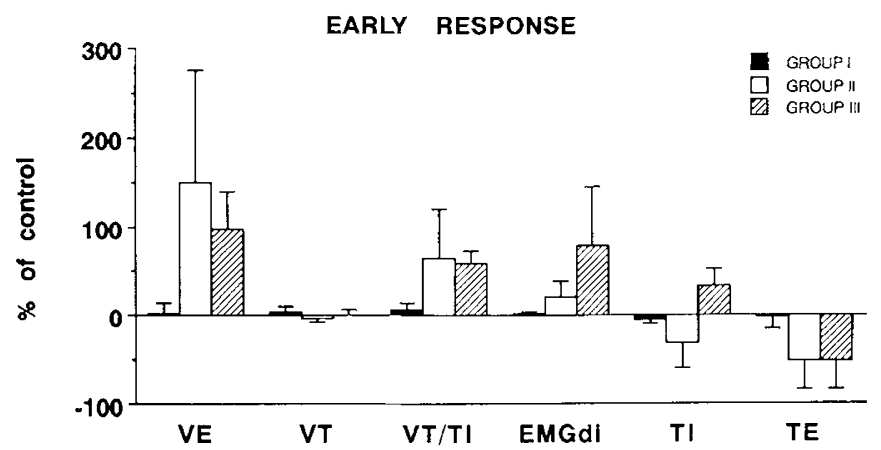

Fig. 1. Changes in ventilatory variables observed during early response to $0.25 \mathrm{mM}$ of LA per $\mathrm{kg}$ of body weight in 1- to 2-d-old ( $g /(n)$ ) I), 3- to 7-d-old (gromp) II), and adult (group III) rabbits. Collumms represent group mean pereentage changes from their controls. I'trical bars represent SD. Control is represented by $0 \%$. VT response was similat in three groups. In group I. values of other variables were significantly different from those in groups II and III. EMGdi increase was significant only in group III. 

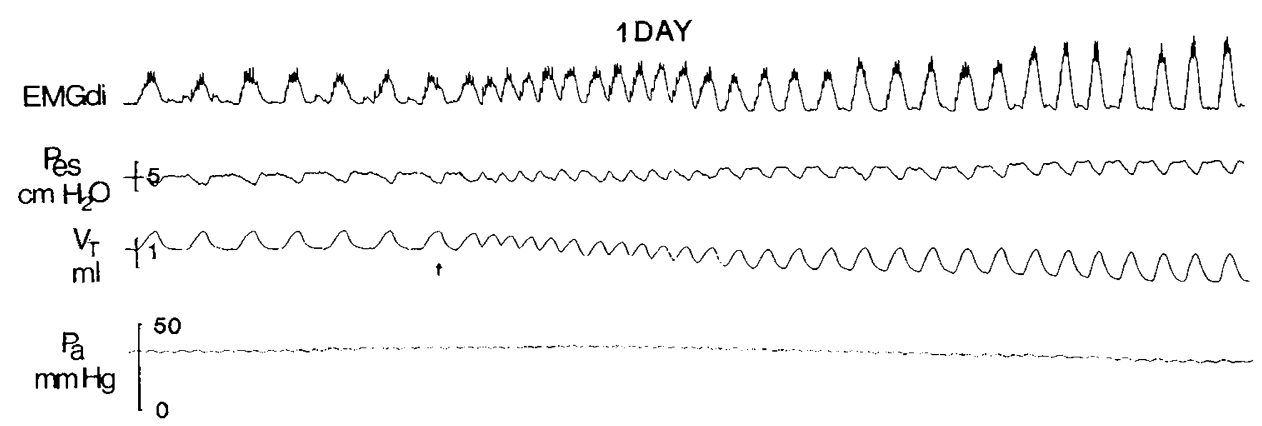

2 DAYS

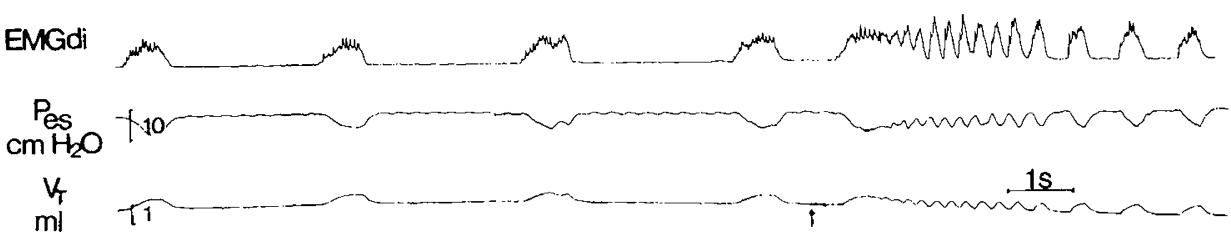

Fig. 2. Effects of $\mathrm{LA}(0.8 \mathrm{mM} / \mathrm{kg})$ injected into the jugular vein of 1 - and 2-d-old rabbits. In these examples, after a delay of about $0.5 \mathrm{~s}$, endexpiratory volume increased and VT decreased. In 2-d-old rabbits, Pa was not recorded. Arrows indicate time of injection. Records for both animals were taken with the same paper speed. Note longer delay for Pa decrease than for early response to LA.

The dose dependence of the early response was tested in six newborns of group 2. An example of the results obtained in a 5$\mathrm{d}$-old rabbit is presented in Figure 3, where values of VE, VT, VT/TI, EMGdi, TI, and TE are plotted against increasing LA doses from 0.05 to $0.5 \mathrm{mM} / \mathrm{kg}$. The two lowest doses, 0.05 and
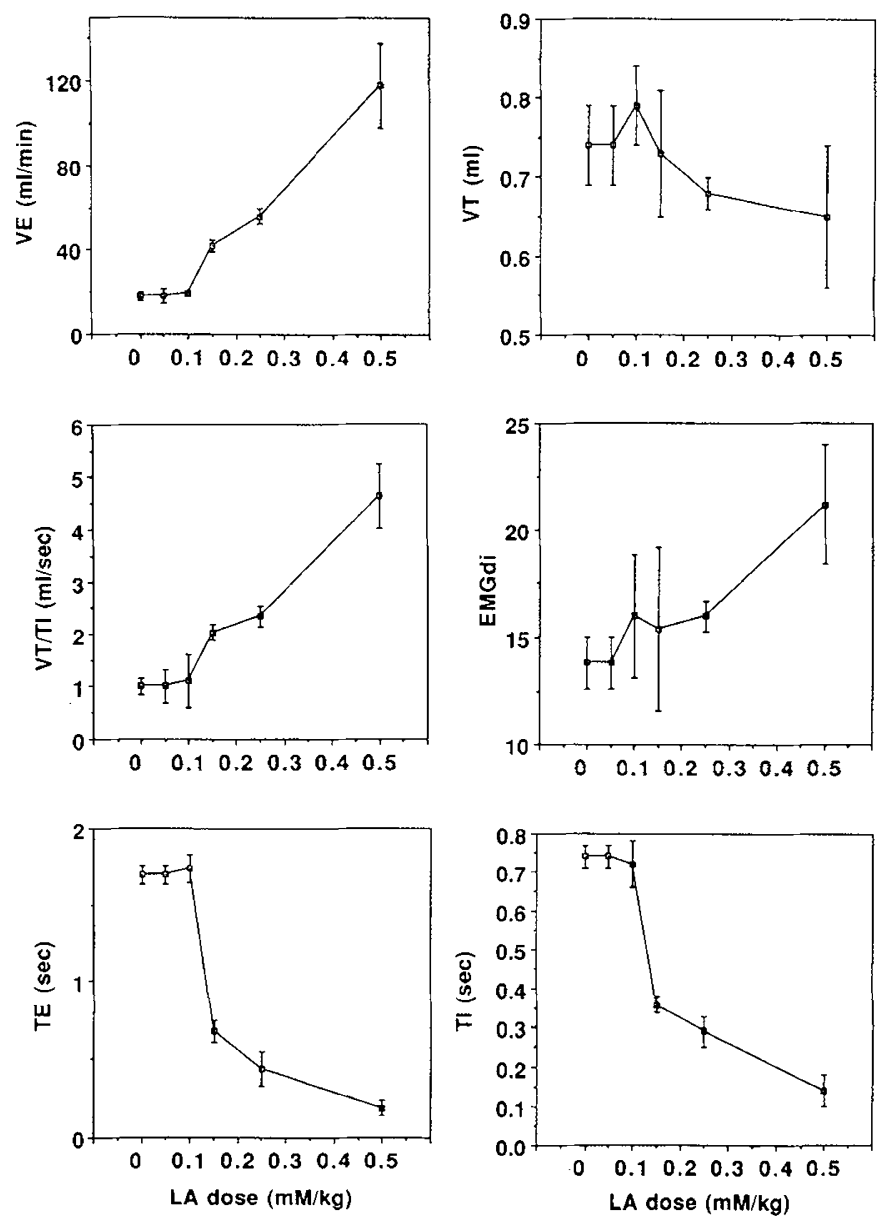

Fig. 3. Effects of increasing dose of LA on ventilatory variables recorded in 5-d-old rabbit. Points represent mean values measured from 10 breaths during control $(0)$ and those recorded during the early response. Vertical bars represent SD.
$0.1 \mathrm{mM} / \mathrm{kg}$, had no effect on the pattern of breathing in this and the other five rabbits tested. However, in response to $0.15,0.25$, and $0.5 \mathrm{mM} / \mathrm{kg}$, there was a dose-dependent increase in VE, $\mathrm{VT} / \mathrm{TI}$, and EMGdi, and a decrease in TI, TE, and VT. Doses larger than $0.5 \mathrm{mM} / \mathrm{kg}$ of LA had no further effects on group 2 . Neither $1.2 \mathrm{mM} / \mathrm{kg}$ nor $1.5 \mathrm{mM} / \mathrm{kg}$ had dose-dependent effects on group 1. Therefore, 0.8 and $0.5 \mathrm{mM} / \mathrm{kg}$ were the saturation doses for the early response to LA introduced into the jugular vein in rabbits of group 1 and group 2 , respectively.

Late response. Statistical analysis indicated that the later response to saturation doses of LA was age independent in newborns. The group mean increases in VE by $214.2 \pm 145.1 \%$, VT by $29.2 \pm 17.6 \%, \mathrm{VT} / \mathrm{Tl}$ by $93.4 \pm 45.7 \%$, and EMGdi by 44.0 $\pm 24.3 \%$ and the shortening of TI and TE by $30.0 \pm 3.8$ and $54.5 \pm 14.2 \%$, respectively, were all significant. In the adult rabbits, increases in VE by $89.0 \pm 58.0 \%$, VT/TI by $54.4 \pm$ $18.8 \%$, and EMGdi by $60.8 \pm 77.2 \%$ and decreases in TI by $21.82 \pm 1.2 \%$ and TE by $51.5 \pm 35.1 \%$ were significant and VT was unaffected.

Effects of LA after vagotomy. After vagotomy, a saturation dose of LA was given to all newborn rabbits. In the adults, the $0.25 \mathrm{mM} / \mathrm{kg}$ dose was repeated. Figure 4 illustrates examples of the response before and after vagotomy taken from a 3-d-old newborn and an adult rabbit. As shown in the figure, the early respiratory response disappeared, and the effects recorded after a delay of 3 to $5 \mathrm{~s}$ resembled the late response in intact rabbits. In newborns, there were significant increases in VE (by $40.8 \pm$ $26.3 \%$ ), VT (by $38.3 \pm 21.7 \%$ ), VT/TI (by $59.3 \pm 28.7 \%$ ), and EMGdi (by $45.9 \pm 32 \%$ ), and TI and TE were unaffected. In the adult animals, the increase in EMGdi by $94.43 \pm 83.8 \%$ and the shortening of TI by $30.8 \pm 24.3 \%$ were significant. All other variables were unaffected.

Figure 5 shows a comparison of changes in respiratory variables during the late response and effects of LA in vagotomized newborn and adult rabbits. In newborns, the VE, TI, and TE responses were greater before than after vagotomy $(p<0.01, p$ $<0.05$, and $p<0.001$ for VE, TI, and TE, respectively). In the adults, the only significant difference between the late response and the effects of LA after vagotomy was that in TE $(p<0.05)$.

\section{DISCUSSION}

Results of this study demonstrate that newborn and adult rabbits may respond to LA injected into the jugular vein with an increase in VE, a shortening in TE, and a decrease or no change 


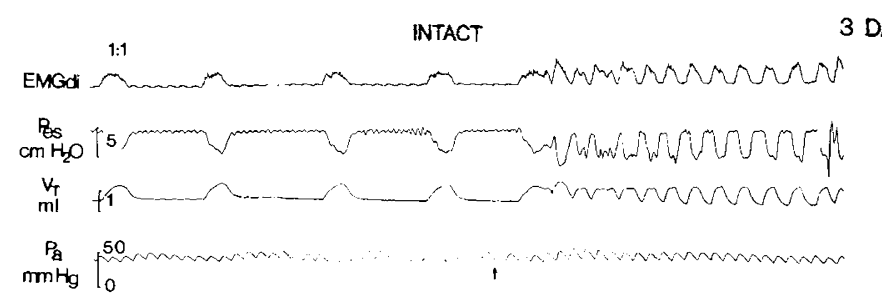

3 DAYS
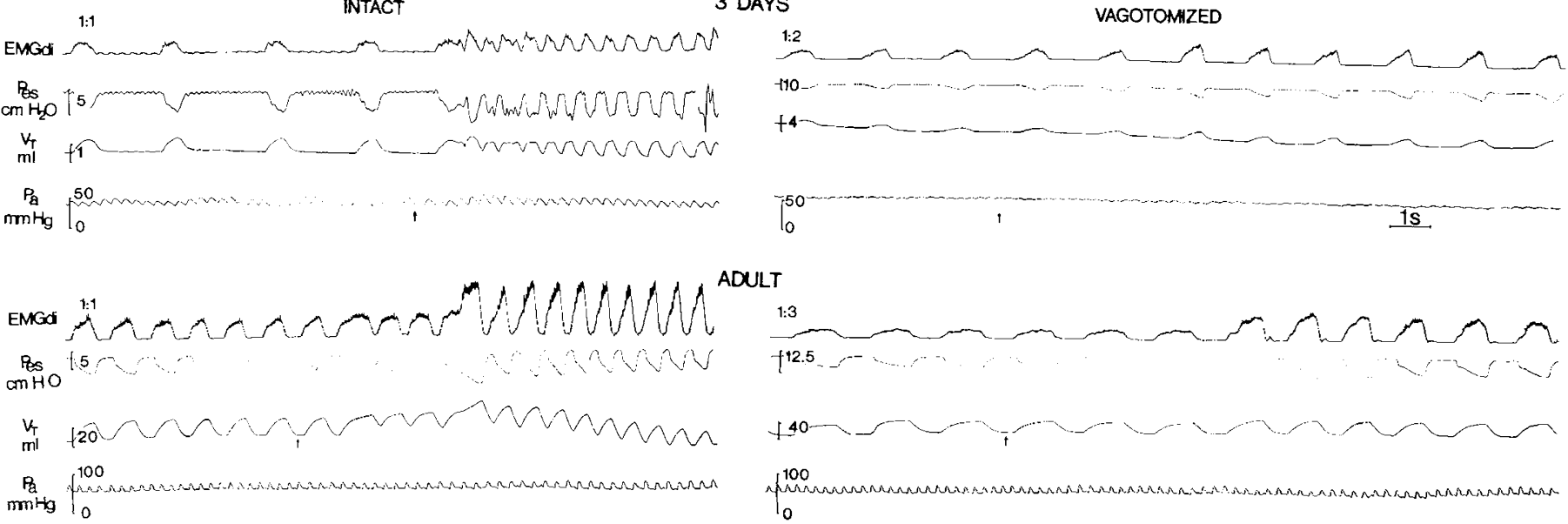

Fig. 4. Examples of responses to LA before and after vagotomy in 3-d-old newborn and adult rabbits. LA doses of 0.5 and $0.25 \mathrm{mM} / \mathrm{kg}$ were used in newborn and adult animals, respectively. Time scale of records is the same in all examples. Arrows indicate time of injection. In the EMGdi trace, ratios show different amplification factors before and after vagotomy. Augmented breath is present at the end of the early response in the adult rabbit.
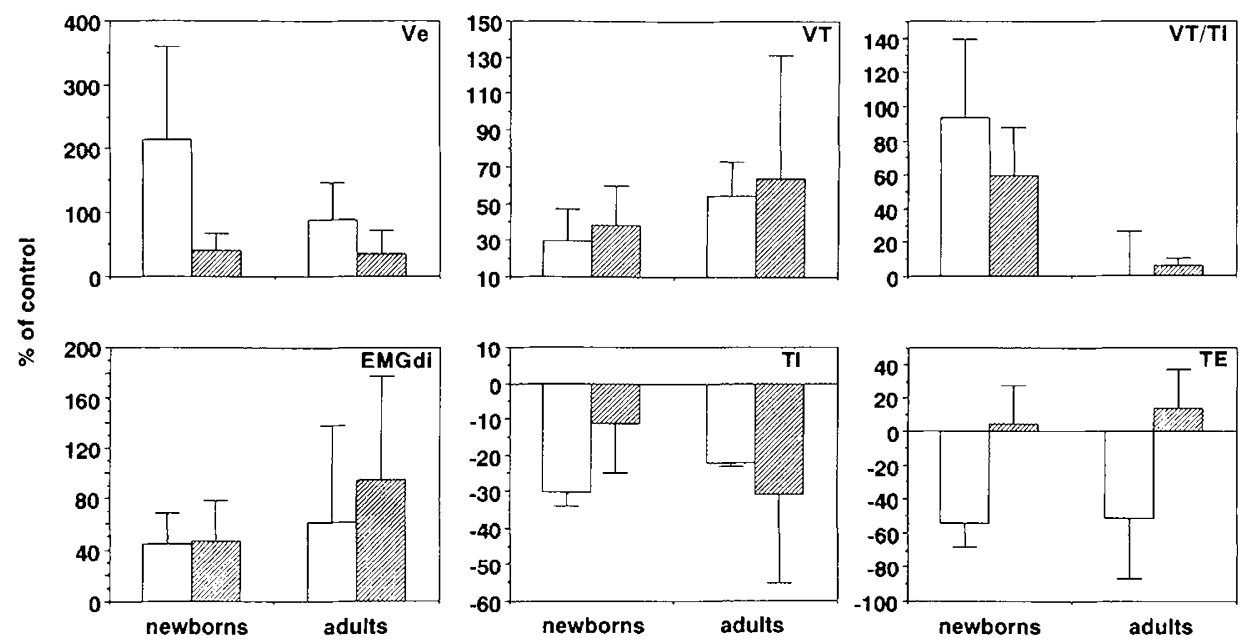

Fig. 5. Changes in respiratory variables recorded during late response to the saturation dose of LA in newborn and to $0.25 \mathrm{mM} / \mathrm{kg} \mathrm{LA}$ in adult rabbits. Columns represent group mean values expressed as percentage change from their controls recorded before injection in intact (open bars) and vagotomized (shaded bars) animals. Vertical bars indicate SD. Control is represented by $0 \%$

in VT (early response) followed by a deep and fast respiration (late response). Similar respiratory effects of LA were described by Trenchard $(9,10)$ in the adults of the same species.

The early response was dose and age dependent and relied on intact vagal input. The LA dose that evoked the early response in 3- to 7-d-old newborns and adult rabbits had no effects on rabbits during their first $2 \mathrm{~d}$ after birth. In these animals, the early response was recorded after about 3-fold larger doses. The increased threshold of the early response suggests immaturity of at least one of the components of the reflex feedback loop involved in the respiratory effects of LA during the first $2 \mathrm{~d}$ of postnatal life in rabbits.

Trenchard and her collaborators $(9,15)$ proposed that the early excitation seen in response to LA introduced to pulmonary circulation is triggered by activation of vagal nonmyelinated pulmonary and pulmonary-bronchial endings via increased $\mathrm{CO}_{2}$ and/or $\mathrm{H}^{+}$in blood in adult rabbits. However, it is also possible that LA produces irritation of $\mathrm{C}$ fibers similar to that evoked by phenyl diguanide and capsaicin in the adults of different species (16). If these mechanisms are indeed involved in LA-related tachypnea, our results imply low sensitivity of these receptors or immature processing of their information immediately after birth in rabbits. This conclusion is in agreement with the lack of effects of phenyl diguanide up to the 6 th day of life and a 6 times higher threshold for development of tachypnea in 1-wk-old kittens than in adult cats (17). On the other hand, a fully developed cardiorespiratory response to right atrial injection of the same agent was present in 2-d-old piglets (18). The difference in the excitability of this reflex response may coincide with greater maturity of pigs than cats at birth.

In contrast to adult rabbits, in all newborns even the largest dose of LA did not change the VT/Pes ratio, suggesting unaffected dynamic properties of the lung. This observation is contradictory to one of our earlier studies showing that only during the first $2 \mathrm{~d}$ of life did histamine, when injected into the pulmonary circulation, fail to decrease lung compliance and airway conductance (19). This difference between the effects of histamine and LA could rely on different mechanisms of action of these two chemicals on airway smooth muscles. Histamine causes bronchoconstriction by stimulation of rapidly adapting vagal receptors and through a direct effect on muscle fibers (20). An increase in airway smooth muscle tone after LA could result from chemoreceptor stimulation (21) by increased release of $\mathrm{CO}_{2}$ from blood (9). Lack of effects of LA on the lung mechanics may imply immaturity of the above mechanism during the first week of life in rabbits.

The late response always followed the early excitation. In some animals, it was the only effect of LA. The response was present 
but somewhat diminished in vagotomized rabbits. On the basis of these results, we concluded that the vagal input may modulate the late response but its origin depends on stimulation of extravagal receptors.

In adult rabbits, the origin of the late response to LA was attributed to stimulation of peripheral chemoreceptors $(10)$. Because in our study the delay of this response exceeded $3 \mathrm{~s}$, it is possible that other peripheral afferents were also involved. Recent evidence suggests that group III and group IV of muscle afferents play a major role in bronchodilator responses and stimulation of breathing (16). This response can be provoked by chemicals such as capsaicin or bradykinin injected to the blood stream supplying hindlimb muscles (22). The inhibitory bronchomotor reflex was also observed during isometric contraction of hindlimb muscles (23) and the diaphragm (24) caused by electrical stimulation of group III and IV fibers in the appropriate ventral root and phrenic nerve, respectively, in adult dogs. In newborns, this pathway of reflex bronchodilatation has never been tested. However, in light of a delayed maturation of the somatic component of the " $J$ reflex" up to the 3 rd week of life (17) and earlier development of ventral roots and muscle efferents than of dorsal roots and muscle afferents in kittens (25), it can be predicted that the above reflex arch was not operating in 1-wk-old rabbits.

In summary, our study indicates that LA may evoke tachypnea immediately after birth, but the threshold of this response is increased during the first $2 \mathrm{~d}$ of life in anesthetized rabbits. Qualitatively similar response to the same LA dose/body weight is present in the adults and newborns by the 3rd day of life. However, because of differences in development between rabbits and humans at birth and possible depressing effects of anesthesia in our study, acidemia should be taken into account as one of the possible factors contributing to transient tachypnea syndrome in infants (2) and tachypnea seen in hypoxic newborns and adults of several mammalian species (11-13).

Acknowledgment. The authors thank Dr. J. P. Mortola for helpful discussions.

\section{REFERENCES}

1. Fisher JT, Mortola JP, Smith JB, Fox SG, Weeks S 1982 Respiration in newborns. Development of the control of breathing. Am Rev Respir Dis 125:650-657

2. Avery ME, Gatewood OB, Brumley G 1966 Transient tachypnea of newborns. Am J Dis Child 11:380-385
3. Kuhn JP, Fletcher BD, deLemos RA 1969 Roentgen findings in transient tachypnea of the newborn. Radiology 92:751-757

4. Fletcher BD, Sachs BF, Kotas RV 1970 Radiologic demonstration of postnatal liquid in the lungs of newborn lambs. Pediatrics 46:252-258

5. Harding R, Wood GA 1990 The role of carotid bodies in establishment of oral breathing during nasal obstruction in lambs and ewes. Respir Physiol 80:7182

6. Siesjo BK, Nilsson L 1971 The influence of arterial hypoxemia upon labile phosphates and upon extracellular and intracellular lactate and pyruvate concentration in the rat brain. Scand J Clin Lab Invest 27:83-96

7. Nolan WF, Houck PC, Thomas JL, Davies DG 1982 Ventral medullary extracellular fluid $\mathrm{pH}$ and blood flow during hypoxia. Am J Physiol 242:R 195-R 198

8. Brown DL, Lawson EE 1988 Brain stem extracellular fluid $\mathrm{pH}$ and respiratory drive during hypoxia in newborn pigs. J Appl Physiol 64:1055-1059

9. Trenchard D $1986 \mathrm{CO}_{2} / \mathrm{H}^{+}$receptors in the lungs of anesthetized rabbits Respir Physiol 63:227-240

10. Trenchard D 1986 Chemoreflexes in rabbits. Respir Physiol 66:367-386

11. Gautier H, Bonora M 1983 Ventilatory response of intact cats to carbon monoxide hypoxia. J Appl Physiol 55:1064-1071

12. Martin-Body RL, Johnston BM 1988 Central origin of the hypoxic depression of breathing in the newborn. Respir Physiol 71:25-32

13. Mortola JP, Rezzonico R, Lanthier C 1989 Ventilation and oxygen consumption during acute hypoxia in newborn mammals: a comparative analysis. Respir Physiol 78:31-43

13a. Bruce EN, Goldman MD, Mead J 1977 A digital computer technique for analyzing respiratory muscle EMGs. J Appl Physiol 43:551-556

14. Trippenbach $T 1988$ The pulmonary chemoreflex in newborn rabbits. Physiologist 31:46(abstr)

15. Russel NJW, Raybould HE, Trenchard D 1984 Role of vagal C-fibre afferents in response to hypercapnia. J Appl Physiol 56:1550-1558

16. Coleridge HM, Coleridge JCG, Schultz HD 1989 Afferent pathways involved in reflex regulation of airway smooth muscle. Pharmacol Ther 41:1-63

17. Kalia M 1976 Visceral and somatic reflexes produced by J pulmonary receptors in newborn kittens. J Appl Physiol 41:1-6

18. Schleman M, Gootman N, Gootman PM 1979 Cardiovascular and respiratory responses to right atrial injections of phenyl diguanide in pentobarbitalanesthetized newborn piglets. Pediatr Res 13:1271-1274

19. Trippenbach T, Kelly G 1987 Respiratory effects of cigarette smoke, dust, and histamine in newborn rabbits. J Appl Physiol 64:837-845

20. Karczewski WA, Widdicombe JG 1969 The role of the vagus nerves in respiratory and circulatory responses to intravenous histamine and phenyl diguanide in rabbits. J Physiol (Lond) 201:271-291

21. Nadel JA, Widdicombe IG 1962 Effect of changes in blood gas tensions and carotid sinus pressure on tracheal volume and total lung resistance to airflow. J Physiol (Lond) 163:13-33

22. Kaufman MP, Ordway GA, Longhurst JC, Mitchell JH 1982 Reflex relaxation of tracheal smooth muscle by thin-fiber muscle afferents in dogs. Am J Physiol 243:R383-R388

23. Kaufman MP, Rybicki KJ, Mitchell JH 1985 Hindlimb muscular contraction reflexly decreases total pulmonary resistance in dogs. J Appl Physiol 59:15211526

24. McCallister LW, McCoy KW, Connelly JC, Kaufman MP 1986 Stimulation of group III and $\mathrm{V}$ phrenic afferents reflexly decreases total lung resistance in dogs. J Appl Physiol 61:1346-1351

25. Skoglund S 1960 Hind-limb reflexes in the kitten. Nature 187:132-134 